\title{
Effect of Catalyst Layer and Fuel Utilization on the Durability of Direct Methane SOFC
}

\author{
S. Georges ${ }^{1}$, S. D. Nóbrega ${ }^{1}$, S. K. Cheah ${ }^{2}$, M. C. Steil ${ }^{1}$, Y. Bultel $^{1}$, M. Rieu ${ }^{2}$, J. P. Viricelle ${ }^{3}$ and \\ P. Gelin ${ }^{2}$ \\ ${ }^{1}$ Laboratoire d'Electrochimie et de Physico-chimie des Matériaux et des Interfaces, LEPMI, UMR 5279, 38402 \\ Saint Martin d'Hères Cedex \\ ${ }^{2}$ Université de Lyon, Institut de Recherches sur la Catalyse et l'Environnement de Lyon, IRCELYON, UMR 5256, \\ 69626 Villeurbanne, France
}

${ }^{3}$ Ecole Nationale Supérieure des Mines, SPIN-EMSE, CNRS:UMR5307, LGF, 42023 Saint-Etienne, France

Keywords: SOFC, catalyst, anode

Among energy conversion systems, high temperature Fuel Cells are considered of great interest for delocalized, renewable and clean electricity and heat power production. The high operating temperature $\left(500^{\circ} \mathrm{C}-800^{\circ} \mathrm{C}\right)$ is likely to allow the use of various types of hydrocarbons instead of hydrogen as the fuel with high efficiency and flexibility. Theoretically, the fuel can be catalytically converted into hydrogen directly at the anodic side. Practically, the most important drawback is the formation of carbon deposits on the anode, poisoning the electrocatalytic activity of the electrode. Hence, one of the main current challenges remains the increase of the life-time of these systems (especially avoiding carbon deposition and anode pollution), and long term reliable operation with fuel flexibility. Such performances have not been achieved yet.

We recently demonstrated the fundamental importance of the fuel utilization on the carbon deposition limits. The quantity of steam released by the anode is directly proportional to the current density, and then to the fuel utilization UF. Below a given value of UF, the system does not produce enough steam to ensure the internal catalytic conversion of the hydrocarbon flux, resulting in irreversible degradation of the cell by carbon methane cracking. This observation and the deep understanding of the anode operation in methane allowed us to achieve long term operation with pure hydrocarbons without carbon deposition at the surface of conventional Ni-YSZ anodes. The thermodynamical limits of carbon deposition as a function of fuel utilization were also investigated.

Current developments and technological simplifications based on new principles of operation and original architectures designed in this finality will be presented. In particular the presentation will emphasize on the Gradual Internal Reforming and Electro-catalytic separation principles applied to the design of original anodic systems, and on the demonstration of the reliability of the systems in different pure hydrocarbons or carbon-based fuels (no $\mathrm{H}_{2} \mathrm{O}, \mathrm{CO}_{2}, \mathrm{O}_{2}$ or carrier gas addition) [1-6]. The effect of the fuel utilization on the limits of carbon deposition will be discussed and the long term durability in pure dry methane will be demonstrated. The perspectives of direct operation of SOFC on waste fuels in order to decrease the amount of $\mathrm{CO}_{2}$ rejects in delocalized energy production systems will be discussed.

1. J-M. Klein et al., Journal of Power Sources 193, (2009) 331

2. S. D. Nobrega et al., Journal of Power Sources (2012) 156-159

4. S. Georges et al., ECS Transactions 57(1) (2013) 3023-3030

4. S.D. Nobrega et al., Journal of the Electrochemical Society, 161(3) (2014) F354-F359

5. J. Puig et al., Fuel Cells 14 (6) (2014) 1014-1021

6. K. Girona et al., Canadian Journal of Chemical Engineering 93 (2) (2015) 285-296 